Pesq. Vet. Bras. 37(8):805-812, agosto 2017

DOI: $10.1590 / \mathrm{S} 0100-736 \mathrm{X} 2017000800005$

\title{
Transmissibilidade de Lentivírus de Pequenos Ruminantes para cabritos e cabras adultas por meio de sêmen infectado experimentalmente ${ }^{1}$
}

\author{
Marjorie Y. Hasegawa ${ }^{2}$, Maria do C.C.S.H. Lara ${ }^{3}$, Natália C. Gaeta ${ }^{2}$, Júlia A. Marques ${ }^{2}$, \\ Bruno L.M. Ribeiro ${ }^{2}$, Rodolfo S. Rossi ${ }^{4}$, Eduardo C. Marques ${ }^{2}$ e Lilian Gregory ${ }^{2 *}$
}

\begin{abstract}
Hasegawa M.Y., Lara M.C.C.S.H., Gaeta N.C., Marques J.A., Ribeiro B.L.M., Rossi R.S., Marques E.C. \& Gregory L. 2017. [Transmissibility of Small Ruminants Lentivirus in kids by experimentally infected semen.] Transmissibilidade de Lentivírus de Pequenos Ruminantes para cabritos e cabras adultas por meio de sêmen infectado experimentalmente. Pesquisa Veterinária Brasileira 37(8):805-812. Departamento de Clínica Médica, Faculdade de Medicina Veterinária e Zootecnia, Universidade de São Paulo, Av. Prof. Dr. Orlando Marques de Paiva 87, São Paulo, SP 05508 270, Brazil. E-mail: lgregory@usp.br

Caprine Arthritis Encephalitis is a multisystemic infectious disease, caused by a lentivirus. The objective of this study was to evaluate the transmissibility of caprine lentivirus to goats and their offspring, through experimentally infected semen. Therefore, eleven free-CAEV goats were artificially inseminated using semen from a free-CAEV buck experimentally infected with CAEV-Cork strain (experimental group one). Pregnancy was confirmed in only six goats and their offspring $(n=6)$ constituted the experimental group two. Two free-CAEV females were artificially inseminated with semen from the same seronegative buck, without viral inoculum to constitute the control group. The diagnosis of caprine lentivirus infection was performed using AGID, cELISA and nested-PCR. All females were monitored for 210 days after artificial insemination. Kids were immediately separated from their mothers after birth, and monitored at zero time, 15 days old and monthly until 12 months old. Regarding goat samples, 56.96\% (9/159) were positive in cELISA, $24.05 \%$ (38/158) were positive in IDGA and none was positive in nested-PCR. Regarding to the offspring samples, $11.28 \%(15 / 133)$ and $5.26 \%$ (7/133) were positive in nested-PCR and IDGA, respectively, while no sample was positive in cELISA. The control group showed no positives in the three techniques. The positivity observed to nested-PCR may show its importance to identify infected, but seronegative animals, in late seroconversion situations. According to results, the transmission of caprine lentivirus to offspring and their mothers through infected semen is possible.
\end{abstract}

INDEX TERMS: Caprine lentivirus, semen, transmission, offspring, AGID, cELISA, nested-PCR.

\footnotetext{
${ }^{1}$ Recebido em 29 de julho de 2015.

Aceito para publicação em 5 de dezembro de 2016.

${ }^{2}$ Departamento de Clínica Médica, Faculdade de Medicina Veterinária e Zootecnia, Universidade de São Paulo, Avenida Prof. Dr. Orlando Marques de Paiva 87, Cidade Universitária, São Paulo, SP 05508 270, Brasil. Pesquisa de doutorado com apoio FAPESP. *Autor para correspondência: lgregory@usp.br

${ }^{3}$ Laboratório de Raiva e Encefalites, Instituto Biológico, Av. Conselheiro Rodrigues Alves 1.252, Vila Mariana, São Paulo, SP 04014-002, Brasil.

${ }^{4}$ Departamento de Higiene Veterinária e Saúde Pública, Faculdade de Medicina Veterinária e Zootecnia de Botucatu, Universidade Estadual Paulista Júlio de Mesquita Filho s/n, Distrito de Rubião Júnior, Botucatu, SP 18618-970, Brasil.
}

RESUMO.- A Artrite Encefalite Caprina se caracteriza por ser multissistêmica e infecciosa, causada por um lentivírus. 0 estudo teve como objetivo avaliar a transmissibilidade do Lentivírus Caprino, para fêmeas e sua prole, por meio de sêmen infectado experimentalmente. Para tanto, onze fêmeas livres de CAEV foram inseminadas artificialmente com sêmen de bode livre de CAEV ao qual foi adicionado CAEV-Cork para obter título infectante com carga viral em $10^{5} \mathrm{TCID}_{50} / \mathrm{ml}$. (grupo experimental 1 ). Destas, seis obtiverem prenhez confirmada, e a sua prole $(\mathrm{n}=6)$ constituiu o grupo experimental 2. Duas cabras livres de CAEV foram inseminadas artificialmente com sêmen do mesmo bode, sem 
o inócuo viral, constituindo-se o grupo controle. 0 diagnóstico da infecção pelo Lentivírus Caprino, foi realizado por IDGA, cELISA e nested-PCR. As fêmeas foram monitoradas durante 210 dias pós inseminação artificial. Já as proles foram imediatamente separadas das mães após o nascimento, e monitoradas nos momentos hora zero, aos quinze dias de idade e mensalmente, até doze meses de idade. Em relação às cabras, $56,96 \%(9 / 158)$ apresentaram positividade para cELISA, $24,05 \%$ (38/158) foram positivas a IDGA e nenhuma para nested-PCR. Em relação aos cabritos, 11,28\% $(15 / 133)$ amostras positivas para nested-PCR, 5,26\% (7/133) amostras positivas para IDGA e nenhum para cELISA. As proles do grupo controle apresentaram resultados negativos para as três técnicas. A positividade encontrada em nested-PCR pode indicar grande importância para identificação de animais infectados, porém soronegativos, em situações de soroconversão tardia. De acordo com os resultados, concluiu-se que há a transmissão do Lentivírus caprino para a prole e para as mães pelo sêmen infectado.

TERMOS DE INDEXAÇÃO: Lentivírus caprino, sêmen, transmissão, prole, IDGA, cELISA, nested-PCR.

\section{INTRODUÇÃO}

No contexto pecuário mundial, o Brasil possui expressivo rebanho caprino, com 8.779 milhões de cabeças em 2013 (IBGE 2013). Dentre as enfermidades infectocontagiosas, a Artrite-Encefalite Caprina (CAE) é uma das maiores responsáveis pela limitação do desenvolvimento da produção de caprinos em nosso país, estando associada a sérios prejuízos econômicos, como descartes prematuros, mortalidade e redução da produtividade (Lara 2002).

A CAE é uma enfermidade transmitida por um pertencente ao grupo Lentivírus de Pequenos Ruminantes (Leroux et al. 1995). Ela é associada a diversos prejuízos econômicos tais como descartes prematuros, mortalidade e redução da produtividade (Lara 2002). 0 impacto econômico da infecção pelo vírus da CAE foi estudado por vários autores, evidenciando redução do índice de fertilidade, aumento do intervalo entre partos e redução da produção de leite (Von Mockenhaupt \& Bauer 1987), além de redução do período de lactação e leite com menores teores de gordura (Greenwood 1995, Bohland 1998).

A doença se manifesta por sintomas sistêmicos, se diferenciando em quatro principais formas clínicas: a leucoencefalomielite, acometendo cabritos (Cork et al. 1974), a artrite, mais frequente em animais adultos (Crawford et al. 1980), a pneumonia crônica intersticial (Sims et al. 1983) e a mamite intersticial endurativa (Gregory et al. 2009b). A maioria dos animais que apresentam sintomatologia é descartado ou sacrificado devido a claudicação, decúbito, perda de peso e queda na produção (Reilly et al. 2002). Atualmente, não existem vacinas nem terapêutica eficazes. Portanto, a forma de combate mais importante é pela detecção precoce do vírus nos rebanhos (Reina et al. 2009), atentando-se para fatores como soroconversão tardia, latência viral e sorológica (Pinheiro 2001).

A transmissão da CAE pode ocorrer por via digestiva através da ingestão de leite e colostro provindos de fêmeas infectadas (Lara 2002), embora haja grande discussão em torno desta via. A transmissão vertical foi observada em certos casos de soroconversão de cabritos separados das mães logo após o parto, que receberam colostro e leite bovino pasteurizado (East et al. 1993).

A identificação do DNA pró-viral do vírus da artrite-encefalite caprina (CAEV) já foi realizada no sêmen de caprinos reprodutores positivos, por meio de PCR (Gregory et al. 2011), sugerindo que tecidos e células do trato reprodutor masculino possam contribuir para a transmissão do vírus. Partículas virais também foram isoladas em testículo, epidídimo, ampola vesicular, próstata, glândula bulbouretral (Peterson et al. 2008) e em glândula vesicular (Ali Al Ahmad et al. 2008) de machos infectados. Novos estudos são solicitados a fim de elucidar a possibilidade de transmissão do DNA pró-viral pela via sexual, inseminando-se fêmeas não-infectadas com ejaculados positivos para CAEV ou por monta natural com bodes infectados (Ali Al Ahmad et al. 2012, Cortez-Romero et al. 2013).

Com o intuito de aprofundar os conhecimentos sobre o aspecto reprodutivo da transmissão deste lentivírus e da existência de poucos trabalhos sobre o assunto, o objetivo do estudo foi avaliar experimentalmente a transmissibilidade do lentivírus caprino para fêmeas adultas soronegativas e sua prole, a partir da inseminação artificial com uso sêmen infectado, por meio do uso de técnicas diagnósticas de IDGA, cELISA e nested-PCR.

\section{MATERIAL E MÉTODOS}

O experimento foi conduzido no Hospital de Bovinos e Pequenos Ruminantes, do Departamento de Clínica Médica da Faculdade de Medicina Veterinária e Zootecnia da Universidade de São Paulo, Brasil, no período de dezembro de 2011 a maio de 2014, sob os princípios éticos de experimentação animal, adotados pela Comissão de Ética no Uso de Animais da FMVZ-USP (protocolo no2585/2011).

Foram utilizadas onze cabras Saanen, entre um ano e meio e quatro anos de idade, soronegativas para CAEV (confirmada por ELISA e IDGA) e artificialmente sincronizadas segundo Traldi et al. (2007). Todas as fêmeas foram inseminadas com $900 \mu \mathrm{l}$ sêmen fresco de bode soronegativo obtido por eletroejaculação, com concentração espermática de 480-860 x $10^{6} \mathrm{sptz} / \mathrm{ml}$, infectado experimentalmente com $100 \mu$ l do vírus CAEV-Cork padrão, totalizando um mililitro. Optou-se pela utilização da estirpe viral padrão CAEV-Cork para infecção do sêmen, pois é empregada na produção do kit comercial de IDGA, cedida pelo Laboratório de Virologia Animal da Universidade Federal Rural de Pernambuco.

0 diagnóstico de prenhez foi realizado 60 dias após a inseminação artificial, através de exame ultrassonográfico por via retal. Seis cabras obtiveram resultado de prenhez positivo e compuseram o grupo experimental do presente estudo.

Como grupo controle, duas cabras Saanen de três anos de idade, soronegativas para CAEV, artificialmente sincronizadas pelo mesmo protocolo, foram inseminadas com sêmen fresco do mesmo bode, porém sem o inócuo viral.

As fêmeas foram mantidas em baias em conjunto durante gestação, parição e lactação, sendo monitoradas até 210 dias pós-inseminação, por meio de colheita de soro e sangue total a cada 15 dias. Todas as parições foram acompanhadas a fim de que os cabritos fossem imediatamente separados após o nascimento. Colostro e leite em pó integral bovinos aquecidos foram fornecidos às proles, sendo realizado desmame aos 60 dias de idade. 0 estudo foi conduzido em ambiente controlado, com proles separadas 
imediatamente após o nascimento e mantidas em baias isoladas sem contato com animais externos.

As amostras dos cabritos foram colhidas nos momentos hora zero (antes do fornecimento de colostro bovino), aos quinze dias de idade, aos trinta dias de idade, e mensalmente, até completarem doze meses de idade.

Para obtenção do soro, foram realizadas colheitas de $7 \mathrm{~mL}$ e $3 \mathrm{~mL}$ de sangue total das fêmeas e dos cabritos, respectivamente, por venopunção da veia jugular externa, em tubos de coagulação com gel separador no volume. As amostras foram mantidas em temperatura ambiente até a coagulação e retração do coágulo, e centrifugadas a 3000xg durante 15 minutos. Os soros obtidos foram transferidos para microtubos estéreis, separados em duplicata e armazenados em freezer até momento do processamento.

Para o diagnóstico do DNA pró-viral por biologia molecular, colheu-se 1,9mL de sangue total dos cabritos e 2,7 mL das mães, em tubos com citrato de sódio, utilizando-se o mesmo acesso venoso descrito anteriormente. As amostras foram homogeneizadas imediatamente após a coleta, para impedir a formação de coágulo sanguíneo e estocadas a $-20^{\circ} \mathrm{C}$. A extração do material genético foi realizada em até 24 horas pós-colheita utilizando o kit comercial (GE Healthcare - Illustra, Amersham Place, UK).

Para diagnóstico da infecção pelo Lentivírus Caprino, foram empregadas as seguintes técnicas: Imunodifusão em Ágar Gel (IDGA) (Abreu et al. 1998), utilizando kit comercial (Biovetech, Brasil) e Ensaio Imunoenzimático Competitivo (cELISA) (Herrmann et al. 2003), utilizando o kit comercial Caprine Arthritis - Encephalitis Virus Antibody Test Kit c ELISA (VMRD, USA) para determinação de anticorpos séricos antivírus da Artrite Encefalite Caprina nas amostras de soro, e nested-PCR para detecção de DNA genômico viral nas amostras de sangue total, segundo Gregory et al. (2009a).

0 processamento das amostras e a realização das técnicas foram efetuados no Laboratório de Virologia Clínica e Molecular do Instituto de Ciências Biológicas da Universidade de São Paulo, no Laboratório de Pesquisa Clínica do Departamento de Clínica Médica da Faculdade de Medicina Veterinária e Zootecnia da Universidade de São Paulo e no Laboratório de Raiva e Encefalites Virais do Instituto Biológico de São Paulo.

Os resultados foram analisados pelo teste de Kolmogorov-Smirnov, utilizando o programa Statistical Analysis Systems (SAS).

\section{RESULTADOS}

0 Quadro 1 apresenta dados referentes às datas de concepção e parição das seis fêmeas do grupo experimental e duas fêmeas do grupo controle, bem como o sexo de suas proles. 0 Quadro 2 apresenta o monitoramento das onze

Quadro 1. Datas de concepção, parição, identificação e sexo das proles referentes ao grupo experimental (E, J, F, G, D e A) e grupo controle (M1 e M2)

\begin{tabular}{ccccc}
\hline Cabras & Data de Concepção & Data de Parição & Cabrito & Sexo \\
\hline E & $03 / 11 / 2012$ & $03 / 04 / 2013$ & 18 & Macho \\
& & & 19 & Fêmea \\
J & $11 / 11 / 2012$ & $12 / 04 / 2013$ & 20 & Macho \\
& & & 21 & Macho \\
F & $11 / 11 / 2012$ & $13 / 04 / 2013$ & 22 & Macho \\
& & & 23 & Fêmea \\
G & $12 / 11 / 2012$ & $14 / 04 / 2013$ & 24 & Macho \\
D & $19 / 11 / 2012$ & $27 / 04 / 2013$ & 27 & Macho \\
& & & 28 & Macho \\
A & $29 / 12 / 2012$ & $26 / 05 / 2013$ & 29 & Fêmea \\
M1 & $18 / 12 / 2011$ & $18 / 05 / 2012$ & 10 & Macho \\
& & & 11 & Macho \\
M2 & $25 / 03 / 2013$ & $27 / 08 / 2013$ & 31 & Macho
\end{tabular}

Quadro 2. Resultados referentes às 11 fêmeas monitoradas até 210 dias após inseminação artificial com inócuo viral (A a K) e 2 fêmeas controle ( $\mathrm{L}$ e M), pelas provas de IDGA, cELISA e nested-PCR

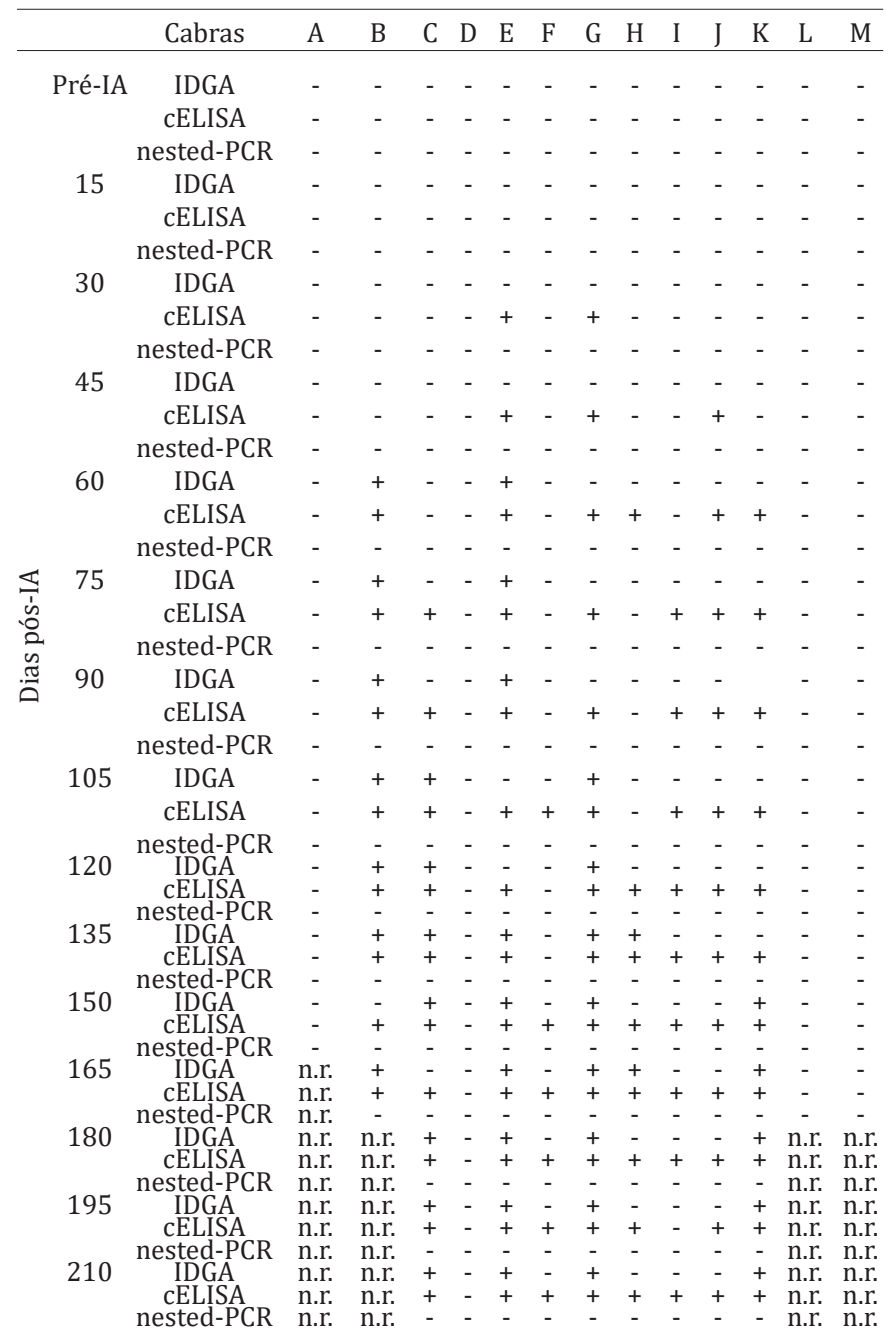

n.r. = Colheita de amostra não realizada. + Positivo, - Negativo.

fêmeas do grupo experimental e duas fêmeas do grupo controle, pelas técnicas de IDGA, cELISA e nested-PCR. A Figura 1 apresenta o número de fêmeas com resultado positivo, após inseminação com inócuo viral CAEV, para as provas

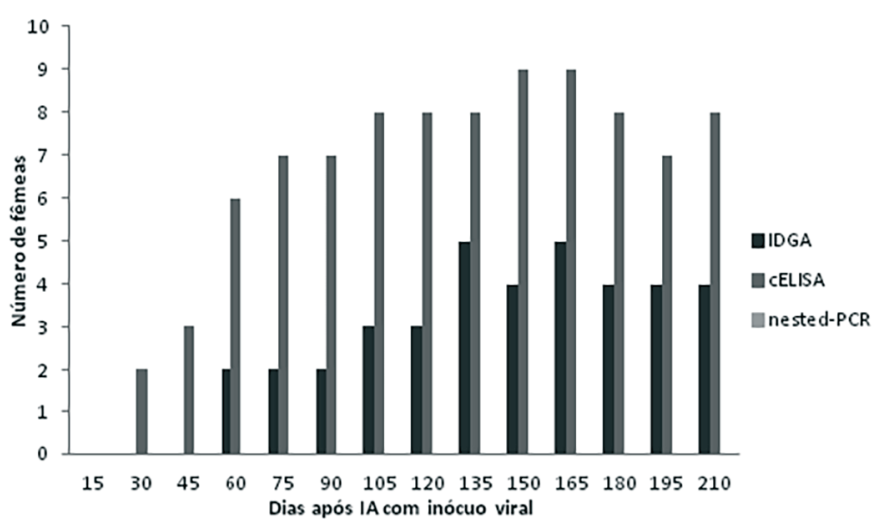

Fig.1. Número de fêmeas com resultado positivo nas provas de IDGA, cELISA e nestes-PCR após inseminação artificial com inócuo viral. 
Quadro 3. Valores de kappa de todas as fêmeas inseminadas com o inócuo viral monitoradas até $\mathbf{2 1 0}$ dias pós-IA. São Paulo, 2014

\begin{tabular}{cccc}
\hline Dias pós-IA com CAEV IDGA-NESTED & IDGA-cELISA & cELISA-NESTED \\
\hline Antes IA & n.c. & n.c. & n.c. \\
15 & n.c. & n.c. & n.c. \\
30 & n.c. & n.c. & n.c. \\
45 & n.c. & n.c. & n.c. \\
60 & n.c. & $+0.364(\mathrm{p}=0.078)$ & n.c. \\
75 & n.c. & $+0.286(\mathrm{p}=0.127)$ & n.c. \\
90 & n.c. & $+0.286(\mathrm{p}=0.127)$ & n.c. \\
105 & n.c. & $+0.340(\mathrm{p}=0.091)$ & n.c. \\
120 & n.c. & $+0.340(\mathrm{p}=0.091)$ & n.c. \\
135 & n.c. & $+0.588(\mathrm{p}=0.016) \mathrm{a}$ & n.c. \\
150 & n.c. & $+0.364(\mathrm{p}=0.078)$ & n.c. \\
165 & n.c. & $+0.435(\mathrm{p}=0.057)$ & n.c. \\
180 & n.c. & $+0.182(\mathrm{p}=0.343)$ & n.c. \\
195 & n.c. & $+0.182(\mathrm{p}=0.343)$ & n.c. \\
210 & n.c. & $+0.286(\mathrm{p}=0.197)$ & n.c. \\
\hline
\end{tabular}

$\bar{a}$ Valores concordantes $(\mathrm{p}<0.05)$, n.c. $=$ não calculado.

Quadro 4. Resultados referentes ao monitoramento das proles do grupo experimental $(1,2,3,4,5,6,7,8,9$ e 10) e do grupo controle (11, 12 e 13), nos momentos hora zero, 15 dias e mensalmente, por doze meses, pelas técnicas de IDGA, cELISA e nested-PCR

\begin{tabular}{|c|c|c|c|c|c|c|c|c|c|c|c|c|c|c|}
\hline Momento & Técnica & 1 & 2 & 3 & 4 & 5 & 6 & 7 & 8 & 9 & 10 & 11 & 12 & 13 \\
\hline & IDG & & & & & & & & & - & - & - & - & \\
\hline \multirow[t]{3}{*}{ Hora zero } & cELIs & & - & - & - & - & - & - & - & - & - & - & & - \\
\hline & nested & - & - & - & - & + & - & + & - & - & - & - & - & - \\
\hline & IDG & & & - & - & - & - & & + & + & - & - & - & - \\
\hline \multirow[t]{3}{*}{15 dias } & cELI & & - & - & - & - & - & - & - & - & - & - & - & - \\
\hline & nested & - & - & - & - & - & - & - & + & + & - & - & - & \\
\hline & IDC & . & - & - & - & - & - & - & + & + & - & - & - & - \\
\hline \multirow[t]{3}{*}{1 mês } & cELI & & . & - & - & - & - & - & - & - & - & - & - & \\
\hline & nested & . & & - & - & - & + & - & + & + & - & - & - & - \\
\hline & IDC & . & & - & - & - & - & - & - & - & - & - & - & - \\
\hline \multirow[t]{3}{*}{2 meses } & cELI & . & & - & - & - & - & - & - & - & - & - & - & - \\
\hline & nestec & + & & - & - & - & + & - & - & + & - & - & - & \\
\hline & IDC & & & - & - & - & - & - & - & - & - & - & - & - \\
\hline \multirow[t]{3}{*}{3 meses } & cELI & & - & - & - & - & - & - & - & - & - & - & - & - \\
\hline & nested & + & + & + & + & - & + & - & - & + & - & - & - & - \\
\hline & $\mathrm{DG}$ & - & - & - & - & - & - & - & - & - & - & - & - & - \\
\hline \multirow[t]{3}{*}{4 meses } & cEL & - & - & - & - & - & - & - & - & - & - & - & - & - \\
\hline & neste & . & & - & - & - & - & - & - & - & - & - & - & - \\
\hline & & - & & - & - & - & - & - & - & - & - & - & - & - \\
\hline \multirow[t]{3}{*}{5 meses } & cELI & . & . & - & - & - & - & - & - & - & - & - & - & - \\
\hline & neste & . & & - & - & - & - & - & - & - & - & - & - & - \\
\hline & & . & & - & - & - & - & - & - & n.r. & - & - & - & - \\
\hline \multirow[t]{3}{*}{6 meses } & cELI & - & - & - & - & - & - & - & - & n.r. & - & - & - & - \\
\hline & nested & - & - & - & - & - & - & - & - & n.r. & - & - & - & - \\
\hline & IDG & - & - & - & - & - & - & - & - & n.r. & - & - & - & - \\
\hline \multirow[t]{3}{*}{7 meses } & cELI & - & - & - & - & - & - & - & - & n.r. & - & - & - & - \\
\hline & nestec & - & - & - & - & - & - & - & - & n.r. & - & - & - & - \\
\hline & & . & - & - & - & - & - & - & - & n.r. & - & - & - & \\
\hline \multirow[t]{3}{*}{8 meses } & $\mathrm{cEL}$ & - & - & - & - & - & - & - & - & n.r. & - & - & - & - \\
\hline & nest & . & - & - & - & - & - & - & - & n.r. & - & - & - & - \\
\hline & & . & - & - & - & - & - & - & - & n.r. & - & - & - & - \\
\hline \multirow[t]{3}{*}{9 meses } & cELI & . & - & - & - & - & - & - & - & n.r. & - & - & - & - \\
\hline & neste & . & - & - & - & - & - & - & - & & - & - & - & - \\
\hline & & - & - & - & - & - & - & - & - & n.r. & - & - & - & n.r. \\
\hline \multirow[t]{3}{*}{10 meses } & cELI & - & - & - & - & - & - & - & - & n.r. & - & - & - & n.r. \\
\hline & nestec & - & - & - & - & - & - & + & - & n.r. & - & - & - & n.r. \\
\hline & IDC & - & - & - & - & - & - & - & - & n.r. & - & - & - & \\
\hline \multirow[t]{3}{*}{11 meses } & cELI & - & - & - & - & - & - & - & - & n.r. & - & - & - & n.r. \\
\hline & nestec & - & - & - & - & - & - & - & - & n.r. & - & - & - & n.r. \\
\hline & & - & - & - & - & - & - & - & - & n.r. & - & - & - & n.r. \\
\hline \multirow[t]{2}{*}{12 meses } & cELI & - & - & - & - & - & - & - & - & n.r. & - & - & - & n.r. \\
\hline & nested-PCR & - & - & - & - & - & - & - & - & n.r. & - & - & - & n.r. \\
\hline
\end{tabular}

n.r. $=$ Colheita de amostra não realizada. + Positivo, - Negativo. diagnósticas realizadas durante o monitoramento. Do total de 158 amostras analisadas, 90 (56,96\%) apresentaram positividade para cELISA, $38(24,05 \%)$ foram positivas a IDGA e zero para nested-PCR. As fêmeas do grupo controle foram negativas em todas as técnicas, durante o período de monitoramento. Foi realizado para o grupo experimental de fêmeas o teste de concordância entre as técnicas diagnósticas, com valores de kappa sumarizados no Quadro 3.

Os resultados apresentados no Quadro 4 se referem a dez cabritos do grupo experimental e três cabritos do grupo controle, monitorados até 12 meses de idade, pelas técnicas de cELISA, IDGA e nested-PCR. A Figura 2 apresenta o número de cabritos do grupo experimental com resultados positivos para as provas diagnósticas durante o monitoramento. Do total de 133 amostras estudadas, observou-se 15 $(11,28 \%)$ amostras positivas para nested-PCR, 7 (5,26\%) amostras positivas para IDGA e zero para cELISA. Não houve diferença estatística entre a técnica de IDGA e de nested-PCR para a detecção dos cabritos positivos. Observou-se concentração de resultados positivos para as proles no terço inicial do período monitorado, sendo o terceiro mês de idade o que apresentou maior número de resultados positivos (dois positivos para IDGA e seis positivos para nested-PCR). Os cabritos do grupo controle testaram negativo em todas as amostras para IDGA, cELISA e nested-PCR.

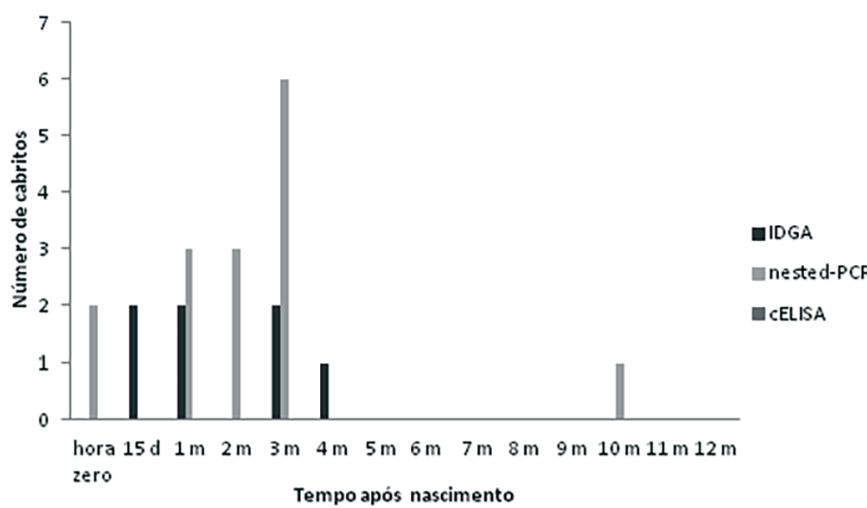

Fig.2. Número de cabritos do grupo experimental com resultado positivo para as provas de IDGA, cELISA e nested-PCR.

\section{DISCUSSÃO}

Do total de 158 amostras analisadas, 90 (56,96\%) apresentaram positividade para cELISA, $38(24,05 \%)$ foram positivas a IDGA e zero para nested-PCR. Pela técnica de cELISA, foi detectada a presença de anticorpos anti-CAEV nas fêmeas 30 dias após a inseminação artificial (IA), comprovando a transmissão via sêmen para as mães com a carga viral de título infectante em $10^{5} \mathrm{TCID}_{50} / \mathrm{mL}$. Isto concorda com outro estudo conduzido por Souza et al. (2013), no qual também demonstra a transmissão do lentivírus caprino para fêmeas soronegativas, por inseminação artifical, com inócuos virais de carga infectante em $10^{6} \mathrm{TCID}_{50} / \mathrm{mL}$ e $10^{2}$ $\mathrm{TCID}_{50} / \mathrm{mL}$ para ação direta no sêmen. No estudo citado, as fêmeas também apresentaram soroconversão após 30 dias da inseminação artificial, utilizando, entretanto, os testes de Western Blot e IDGA.

Os resultados obtidos discordam dos observados em outro estudo (Adams et al. 1980), no qual nenhuma fêmea 
apresentou soroconversão após 18 meses da IA utilizando-se bodes infectados. Isto pode estar relacionado a susceptibilidade dos animais, uma variável que não pode ser contornada. Outro fator que pode influenciar o momento de soroconversão é a diferença entre a quantidade de carga viral viável presente no sêmen dos reprodutores naturalmente infectados do estudo citado (Adams et al. 1980), e a quantidade de carga viral inoculada artificialmente no sêmen do presente estudo. Em situações naturais de infecção, os títulos de infecção podem representar valores bem abaixo dos utilizados nesta infecção experimental.

A baixa carga viral in vivo e sua variação são os principais obstáculos para a padronização das provas de PCR para o diagnóstico da CAE (Andrés et al. 2005). Há hipótese de que os primers não anelariam corretamente com o DNA extraído na técnica, enquanto outra afirma que a alta taxa de mutação destes vírus ( 1 mutação para cada $10^{5}$ nucleotídeos) seria responsável pela diminuição da eficácia da técnica de PCR para detecção do DNA pró-viral (Barquero et al. 2013b). 0 teste de IDGA nas fêmeas adultas detectou maior número de animais infectados em relação ao nested-PCR, pelo qual nenhum positivo fora detectado. Este resultado concorda com o reportado por Rutkoski et al. (2001), em cujo estudo houve maior proporção de detecção de animais infectados pelo CAEV pelo IDGA quando comparado ao PCR. Relatam-se casos de animais que mantiveram contato com o lentivírus caprinos, porém apresentaram resultados negativos para sangue utilizando a PCR (Peterson et al. 2008). Fatores genéticos do hospedeiro podem influenciar a eficiência da resposta imune, controlando a carga viral desses lentivírus (Cardinaux et al. 2013). A ativação de cargas virais do lentivírus caprino pode se dar em situações de estresse, como durante a estação de monta (Peterson et al. 2008) e período de transição da estação chuvosa para seca (Paula et al. 2009) provocando subsequente excreção e detecção de DNA pró-viral em ejaculados de bodes infectados (Peterson et al. 2008). Além do fator de restrição da replicação viral, já citado, outra possibilidade gira em torno do fato de CAEV infectar somente monócitos, que constituem apenas 10\% dos leucócitos do sangue periférico. O DNA pró-viral está apenas nestas células, implicado na falha da detecção simplesmente pela carga viral abaixo do limite de detecção da técnica (Smith \& Sherman 1994, Andrés et al. 2005). Ainda, é possível que tenha ocorrido o clearance (limpeza) pró-viral tenha ocorrido, no qual o ADCC (Antibody dependent cellular cytotoxicity) e/ou anticorpos neutralizantes tenham papel fundamental (Herrmann-Hoesing et al 2007, Barquero et al. 2013b). Gregory et al. (2011), utilizando as técnicas de PCR e Nested-PCR para detecção do cDNA em amostras de leite, observaram 19,4\% (14/72) amostras positivas na primeira reação e 22,2\% (16/72) na segunda. A técnica para nested-PCR possui outras desvantagens relatadas, como baixa porcentagem de positivos (Gonzales et al. 2013), baixa sensibilidade (Andrés et al. 2005) e falsos positivos (Brinkhof et al. 2008, Brinkhof et al. 2010, Barquero et al. 2011). Os resultados negativos para o nested-PCR não devem ser interpretados como falsos negativos, pois é observada intermitência da presença do DNA pró-viral em sêmen e sangue (Andrioli et al. 2006, Peterson et al. 2008, Minardi 2009).
Somente duas cabras, "A" e "D", não apresentaram anticorpos anti-CAEV em IDGA e cELISA durante o monitoramento. 0 kit da prova de IDGA utilizado possui sensibilidade de $66,67 \%$ e especificidades de 90,48\% (Silva et al. 2013). Devido a esta característica, ao baixo custo e praticidade, o teste proporciona grande importância em levantamentos epidemiológicos e na triagem de animais. Pode-se, ainda, considerar um cenário de soroconversão tardia, impedindo a detecção da positividade.

A progênie apresentou 15 (11,28\%) amostras positivas ao nested-PCR, 7 (5,26\%) amostras positivas ao IDGA e nenhuma positiva ao cELISA. A técnica de nested-PCR conseguiu detectar mais amostras positivas que o teste de IDGA, indicado estatisticamente pelo valor de porcentagem maior do que o dobro da porcentagem de positivos ao IDGA. A baixa positividade encontrada pode indicar que os testes de PCR tendem a apresentar menor sensibilidade do que as provas de ELISA, porém, a PCR apresenta maior eficiência na detecção em infecções recentes. Também se observou que os animais 1 e 2 apresentaram resultados positivos ao nested-PCR mais precocemente, aos dois e três meses, respectivamente, quando comparado ao IDGA, com resultados aos três e quatro meses, respectivamente. Este comportamento pode ser explicado pela intermitência da resposta imunológica, que apresenta níveis variáveis de anticorpos em animais sabidamente positivos, ao longo de semanas, meses e até anos (Rowe et al. 1992, Rimstad et al. 1993, Preziuso et al. 2003). Também é relatado que, normalmente, após a soroconversão, os níveis de anticorpos se elevam até determinado pico, decaindo depois para nível estável menor (Adams et al. 1980, Cheevers et al. 1988). A soroconversão tardia é uma das causas para a subestimação do número de animais infectados quando utilizamos os testes sorológicos rotineiros (Rimbaud et al. 1993).

Os cabritos 3, 4, 5, 6 e 7 apresentaram resultados positivos ao nested-PCR e nenhum positivo aos dois testes sorológicos. No entanto, estes animais não devem ser considerados falsos positivos, pois é relatada a eventual soroconversão tardia (Barquero et al. 2011). Outra hipótese está relacionada à possível falha do kit comercial em detectar anticorpos relativos ao maior número de epítopos de superfície de Lentivírus e, por este motivo, resultar em muitos falsos negativos. Kits baseados em vírus completo para a detecção de anticorpos anti-CAEV se demonstram mais sensíveis do que os tradicionais, pois seus antígenos podem compensar a heterogeneidade viral devido à variabilidade de epítopos para a reação (Zanoni et al. 1994, Mordasini et al. 2006). Também deve ser levado em consideração que, além de fatores inerentes aos testes, há animais com resposta imunológica seletiva para determinados antígenos (Rimstad et al. 1994), o que influenciará a detecção destes. Relata-se que quando a prova de ELISA é utilizada como única técnica diagnóstica, novos casos de infecção podem não ser detectados, sendo recomendado o uso concomitante de uma técnica diagnóstica indireta e direta (Barquero et al. 2013a). É importante ressaltar a positividade ao nested-PCR dos cabritos 5 e 7 na hora zero, eliminando qualquer chance de infecção pelo meio externo. Ressalta-se que todos os animais foram imediatamente 
separados das mães para que não fossem infectados com o vírus sabidamente eliminado pelo colostro e pelo leite (Gaeta et al. 2016). Esses resultados indicam a transmissão do lentivírus para cabritos a partir da inseminação de fêmeas com sêmen infectado.

Foi observada a presença de anticorpos anti-CAEV em IDGA nos cabritos 1 e 2, filhos da cabra "E", e nos cabritos 8 e 9, filhos da cabra "D". A fêmea "E" apresentou soroconversão a partir dos 30 dias pós-infecção à técnica de cELISA, e a partir dos 60 dias pós-infecção para IDGA. A fêmea "D" não apresentou nenhum resultado positivo durante o período monitorado, para as três técnicas diagnósticas, indicando que, naquele momento, a infecção estivesse localizada no sistema reprodutor conforme foi observado por Cavalcante et al. (2013) ou uma possível transmissão para o embrião diretamente pelo sêmen infectado como sugerido por Ricarte et al. 2010. As provas de imunodiagnóstico são dependentes da quantidade de anticorpos no organismo, que será afetada de acordo com o nível de replicação viral em cada animal (Tigre et al. 2006), sendo observado menor tempo médio de soroconversão em rebanhos com maior prevalência (Peterhans et al. 2004). Com base nisto, há possibilidade de que, por se tratar de estudo conduzido em ambiente controlado, ou seja, proles separadas imediatamente após o nascimento e mantidas em baias isoladas sem contato com animais externos (representando rebanho com baixa prevalência), os resultados negativos na prova de cELISA e IDGA signifiquem que maior tempo pode ser necessário para a detecção dos anticorpos. A intermitência da resposta imunológica, com níveis de anticorpos variáveis, também pode ser responsável pelo comportamento de animais sabidamente positivos que apresentam resultados negativos para testes de cELISA e IDGA, observada em animais acompanhados ao longo de semanas, meses e até anos (Rowe et al. 1992, Preziuso et al. 2003, Rimstad et al. 1993). Relata-se também que, normalmente, após a soroconversão, os níveis de anticorpos se elevam até um determinado pico, decaindo depois para nível menor, porém estável (Adams et al. 1980, Cheevers et al. 1988). Este padrão justifica os dados encontrados no presente estudo, no qual houve maior detecção de anticorpos até o 3 o mês de idade dos cabritos e redução dos níveis nos outros meses, chegando a títulos indetectáveis.

A positividade encontrada ao nested-PCR nas proles pode ter relevância para a identificação de animais infectados, porém soronegativos, como nas situações de soroconversão tardia, nas quais a produção de anticorpos é baixa ou inexistente, ou em situações de fase inicial de infecção, período no qual a técnica apresenta maior sensibilidade (Frota et al. 2005, Tigre et al. 2006, Souza 2010). Considerando-se a variação nos resultados obtidos mediante diferentes métodos diagnósticos, relatam-se resultados semelhantes em outro estudo, no qual foram testados cabritos filhos ou netos de animais soropositivos para o CAEV, sendo identificado que $76,08 \%$ dos cabritos em seu $1^{\circ}$ ano de vida possuíam DNA pró-viral em células mononucleares do sangue periférico, porém, apenas $2,17 \%$ dos animais tiveram resultado positivo ao IDGA (Frota et al. 2005). A prole apresentou também maiores taxas de positividade ao
nested-PCR aos três meses. Sugere-se que houve influência do estresse provocado pelo desmame realizado a partir dos dois meses de idade, contribuindo para certa interferência nos resultados, pois produção de anticorpos e sua concentração no sangue de animais infectados são influenciadas por situações de estresse, pela condição alimentar e idade (Franke 1998). A replicação intracelular dos lentivírus não permite o desenvolvimento de uma resposta imune eficaz. Além disso, por não produzirem partículas virais e acumularem altas taxas de mutação durante a replicação, ocorre o escape do sistema imunológico (Cheevers et al. 1993, Callado et al. 2001) e, portanto, há maior detecção pelas técnicas diagnósticas.

A presença de células infectadas pelo lentivírus, originárias de epitélios ou de macrófagos, encontrada em secreções pós-parto em caprinos (Rowe 1999) pode contribuir para a infecção da prole ao nascimento, mensurada em 18\% (Cross et al. 1975) e em 11\% (Brodie et al. 1994). De acordo com outro estudo, embora a placentação cotilédone-epiteliocorial de pequenos ruminantes previna contato direto entre o sangue maternal e fetal, o intercâmbio celular pode ocorrer se houver inflamação local com infiltração leucocitária (Ali Al Ahmad et al. 2005), como ao nascimento, durante maturação placentária, no caso de distensão da cérvix (Ali 1987, Owny et al. 1995) ou durante a cesárea (Hoff-Jôrgensen 1977).

A cabrita 29 foi a única nascida por procedimento de cesárea, estando teoricamente mais exposta ao sangue materno, porém não apresentou nenhum resultado positivo. No entanto, a mãe desta cabrita também não apresentou resultados positivos nas três provas diagnósticas. Portanto, não foi possível avaliar o potencial na transmissibilidade do lentivírus caprino quanto ao procedimento realizado durante a parição.

\section{CONCLUSÕES}

Foi possível observar a transmissão de CAEV para as mães livres de CAEV e sua prole por meio do sêmen com inócuo viral.

A associação de diferentes técnicas diagnósticas se mostrou importante para a detecção de infecção pelo vírus, melhorando o desempenho do diagnóstico, sendo que o teste de IDGA e nested-PCR se mostraram mais eficientes na detecção dos animais infectados.

Espera-se que os resultados do estudo possam ser aplicados no auxílio de definição de medidas a serem tomadas para programas de controle do vírus da CAE e medidas de erradicação, para manutenção da sanidade caprina e aprimoramento da rentabilidade da cadeira produtiva.

\section{REFERÊNCIAS}

Abreu S.R.O., Castro R.S., Nascimento S.A. \& Souza M.G. 1998. Produção de antígeno nucleoproteico do vírus da artrite-encefalite caprina e comparação com o vírus do Maedi-visna para utilização em teste de imunodifusão em Agar gel. Pesq. Vet. Bras. 18(2):57-60.

Adams D.S., Crawford T.B. \& Klevjer-Anderson P.A. 1980. A pathogenic study of early connective tissue lesions of viral caprine arthritis-encephalitis. Am. J. Pathol. 99(2):257-271.

Ali A.0. 1987. Caprine arthritis-encephalitis related changes in the uterus of a goat. Vet. Rec. 121:131-132. 
Ali Al Ahmad M.Z., Fieni F. \& Martignat L. 2005. Proviral DNA of caprine arthritis encephalitis virus (CAEV) is detected in cumulus oophorus cells but not in oocytes from naturally infected goats. Theriogenology 64(7):1656-1666.

Ali Al Ahmad M.Z., Fieni F., Pellerin J., Guiguen F., Cherel Y. \& Chatagnon G. 2008. Detection of viral genomes of caprine arthritis-encephalitis virus (CAEV) in semen and in genital tract tissues of male goat. Theriogenology 69:473-80.

Andrés D., Klein D., Watt N.J., Berriatua E., Torsteinsdottir S., Blacklaws B. \& Harkiss G.D. 2005. Diagnostic tests for small ruminant lentiviruses. Vet. Microbiol. 107:49-62.

Andrioli A., Gouveia A.M.G., Martins A.S., Pinheiro R.R. \& Santos D.O. 2006. Fatores de risco na transmissão do lentivírus caprino pelo sêmen. Pesq. Agropec. Bras. 41(8):1313-1319.

Barquero N., Arjona A., Domenechi A., Toural C., De Las Heras A., Fernandez-Garayzabal J.F., Ruiz-Santa-Quiteria J.A. \& Gomezlucia E. 2011. Diagnostic performance of PCR and ELISA on blood and milk samples and serological survey for small ruminant lentiviruses in central Spain. Vet. Rec. 168(1):20.

Barquero N., Domenechi A., Arjona A., Fernández-Garayzabal J.F., Ruiz-Santa-Quiteria J. \& Gomez-Lucia E. 2013a. Comparision of two PCR and one ELISA techniques for the detection of small ruminant lentiviruses (SRLVs) in milk of sheep and goats. Res. Vet. Sci. 94:817-819.

Barquero N., Gomez-Lucia E., Arjona A., Toural C., Las Heras A., Fernández-Garayzabal J.F. \& Domenech A. 2013b. Evolution of specific antibodies and proviral DNA in milk of small ruminants infected by small ruminant lentivírus. Viruses 5(10):2614-2623.

Bohland E. 1998. Artrite encefalite caprina: avaliação dos aspectos produtivos e reprodutivos de animais infectados e não infectados. Dissertação de Mestrado, Faculdade de Medicina Veterinária e Zootecnia, Universidade de São Paulo, SP. 95p.

Brinkhof J.M., Van Maanen C., Wigger R., Peterson K. \& Houwers D.J. 2008. Specific detection of small ruminant lentiviral nucleic acid sequences located in the proviral terminal repeat and leader-gag regions using real-time polymerase chain reaction. J. Virological Methods 147:338-344.

Brinkhof J.M.A., Houwers D.J., Moll L., Dercksen D. \& Van Maanen C. 2010. Diagnostic performance of ELISA and PCR in identifying SRLV-infected sheep and goats using serum, plasma and milk samples and in early detection of infection in dairy flocks through bulk milk testing. Vet. Microbiol. 142:193-198.

Brodie S.J., De La Concha-Bermejillo A., Kôenig G., Snowder G.D. \& DeMartini J.C. 1994. Maternal factors associated with prenatal transmission of ovine lentivirus. J. Infect. Dis. 169:653-657.

Callado A.K.C., Castro R.S. \& Teixeira M.F.S. 2001. Lentivírus de pequenos ruminantes (CAEV e Maedi-Visna): revisão e perspectivas. Pesq. Vet. Bras. 21(3):87-97.

Cardinaux L., Zahnoa M.L., Deubelbeiss M., Zanoni R., Vogt H.R. \& Bertoni G. 2013. Virological and phylogenetic characterization of attenuated small ruminant lentivirus isolates eluding eficiente serological detection. Vet. Microbiol. 162:572-581.

Cavalcante F.R.A., Andrioli A., Pinheiro R.R., Souza K.C., Veras A.K.A., Lopes T.A., Sousa S.D. \& Silva P.A.F. 2013. Detecção do vírus da Artrite Encefalite Caprina por nested PCR e nestedRT-PCR em ovócitos e fluído uterino. Arqs Inst. Biológico, São Paulo, 80(4):381-386.

Cheevers W.P., Knowles D.P., McGuire T.C., Cunningham D.R., Adams D.S. \& Gorham J.R. 1988. Chronic disease in goats orally infected with two isolates of the caprine arthritis encephalitis lentivirus. Lab. Invest. 58:510517.

Cheevers W., McGuire T., Norton L.K., Cordery-Cotter R. \& Knowles D. 1993. Failure of neutralizing to regulate CAE lentivirus expression in vivo. Virology 196:835-839.

Cork L.C., Hadlow W.J., Crawford T.B., Gorham J.R. \& Piper R.C. 1974. Infectious leukoencephalomyelitis of young goats. J. Infect. Dis. 129(2):134-141.

Cortez-Romero C., Pellerin J.L., Ali-Al-Ahmad M.Z., Chebloune Y., Gallegos-Sánchez J., Lamara A., Pépin M. \& Fieni F. 2013. The risk of small ruminant lentivirus (SRLV) transmission with reproductive biotechnologies: State-of-the-art review. Theriogenology 79:1-9.
Crawford T.B., Adams D.S., Cheevers W.P. \& Cork L.C. 1980. Chronic arthritis in goats caused by a retrovirus. Science 207(29):997-999.

Cross R.F., Smith C.K. \& Moorhead P.D. 1975. Vertical transmission of progressive pneumonia of sheep. Am. J. Vet. Res. 36:465-468.

East N.E., Rowe J.D., Dahlberg J.E., Thelen G.H. \& Pedersen N.C. 1993. Modes of transmission of caprine arthritis-encephalitis virus infection. Small Rumin. Res. 10(3):251-262.

Franke C.R. 1998. Controle Sanitário da Artrite-Encefalite Caprina. EDUFBA, Salvador, p.70.

Frota M.N.L., Silva J.B.A. \& Araújo S.A.C. 2005. Artrite Encefalite Caprina em cabritos de rebanhos com programa de controle no Estado do Ceará. Arqs Inst. Biológico, São Paulo, 72(2):147-152.

Gaeta N.C., Hasegawa M.Y., Ribeiro B.L.M., Gomes A.L., Castro R.S. \& Gregory L. 2016. Studying the elimination pattern of caprine arthritis encephalitis virus in the milk of infected females. Acta Scient. Vet. [Em publicação].

Gonzales J.V.C., Domingo C.Y.J., Abes N.S., Gutierrez C.A., Villanueva M.A. \& Mingala C.N. 2013. Concordance of competitive enzyme linkes immunosorbent assay and nested-polymerase chain reaction in the detection of caprine arthritis-encephalitis virus. Small Rumin. Res. 115(1):143-139.

Greenwood P.L. 1995. Effects of caprine arthritis-encephalitis virus on productivity and health of dairy goats in New South Wales, Australia. Prev. Vet. Med. 22(1/2):71-87.

Gregory L., Lara M.C.C.S.H., Villalobos E.M.C., Hasegawa M.Y., Castro R.S., Rodrigues J.N.M., Araujo J., Keller L.W. \& Durigon E.L. 2009a. Detecção do vírus da artrite encefalite caprina em amostras de leite de cabras pela reação em cadeia da polimerase (PCR) e nested-PCR. Ars Vet. 25(3):142-146.

Gregory L., Birgel Junior E.H., Lara M.C.C.S.H., Angelini M., Araújo W.P., Rizzo H., Maiorka P.C., Castro R.S., Kiraly A.C.M., Benesi F.J. \& Birgel E.H. 2009 b. Clinical features of indurative mastitis caused by caprine arthritis encephalitis virus. Bras. J. Vet. Pathol. 2(2):64-68.

Gregory L., Lara M.C.C.S.H., Hasegawa M.Y., Castro R.S., Rodrigues J.N.M., Araújo J., Keller L.W., Silva L.K.F. \& Durigon E.L. 2011. Detecção do vírus de artrite encefalite caprina no sêmen através das técnicas de PCR e nested-PCR. Arqs Inst. Biológico, São Paulo, 78(4):599-603.

Herrmann L.M., Cheevers W.P., McGuire T.C., Adams D.S., Hutton M.M., Gavin W.G. \& Knowles D.P. 2003. Competitive-inhibition enzyme-linked immunosorbent assay for detection of serum antibodies to Caprine arthritis-encephalitis virus: diagnostic tool for successful eradication. Clin. Diagn. Lab. Immunol. 10:267-271.

Herrmann-Hoesing L.M., Palmer G.H. \& Knowles D.P. 2007. Evidence of proviral clearance following postpartum transmission of an ovine lentivirus. Virology 362:226-234.

Hoff-Jôrgensen R. 1977. Slow virus infections with particular reference to Maedi-Visna and enzootic bovine leukaemia. Vet. Res. Commun. 1:251263.

IBGE 2013. Produção Pecuária Municipal 2013. Seção Estatística, Instituto Brasileiro de Geografia e Estatística. Disponível em <htp://ftp.ibge.gov. br/Producao_Pecuaria/Producao_da_Pecuaria_Municipal/2013/tabelas_pdf/tab18.pdf> Acesso em 10 mai. 2015.

Lara M.C.C.S.H. 2002. Artrite-encefalite dos caprinos: aspectos clínicos e epidemiológicos. Tese de Doutorado, Faculdade de Medicina Veterinária e Zootecnia, Universidade de São Paulo, SP. 247p.

Leroux C., Vuillermoz S., Mornex J.F. \& Greenland T. 1995. Genomic heterogeneity in the pol region of ovine lentivirus obtained from bronchoalveolar cells of infected sheep from France. J. Gen. Virol. 76:1533-1537.

Minardi J.C. 2009. Monitoramento sorológico e da presença do DNA pró-viral do lentivírus caprino (CAEV) no sangue e sêmen de reprodutores infectados. Tese de Doutorado, Universidade Federal de Minas Gerais, Belo Horizonte, MG. 35p.

Mordasini F., Vogt H.R., Zahno M.L., Maeschli A., Nenci C., Zanoni R., Peterhans E. \& Bertoni G. 2006. Analysis of the Antibody Response to an Immunodominant Epitope of the Envelope Glycoprotein of a Lentivirus and Its Diagnostic Potential. J. Clin Microbiol. 44(3):981-991.

Owny J.R., Gilbert R.O., Wahl C.H. \& Nathanielsz P.W. 1995. Leukocytic invasion of the ovine cervix at parturition. J. Soc. Gynecol. Invest. 2:593-596. 
Paula N.R.O., Andrioli A., Cardoso J.F.S., Pinheiro R.R., Sousa F.M.L., Souza K.C., Alves F.S.F., Campello C.C., Ricarte A.R.F. \& Teixeira M.F.S. 2009. Profile of the caprine arthritis-encephalitis virus (CAEV) in blood, sêmen from bucks naturally and experimentally infected in the semi-arid region of Brazil. Small Rumin. Res. 85(1):27-33.

Peterhans E., Greenland T., Badiola J., Harkiss G., Bertoni G., Amorena B., Eliaszewicz M., Juste R.A., Krassing R., Lafont J.P., Lenihan P., Petursson G., Pritchard G., Throley J., Vitu C., Mornex J.F. \& Pepin M. 2004. Routes of transmission and consequences of small lentiviruses (SRLVs) infection and eradication schemes. Vet. Res. 35:257-274.

Peterson K., Brinkhof J., Houwers D.J., Colenbrander B. \& Gadella B.M. 2008. Presence of pro-lentiviral DNA in male sexual organs and ejaculates of small ruminants. Theriogenology 69:433-443.

Pinheiro R.R. 2001. Vírus da Artrite encefalite caprina: desenvolvimento e padronização de ensaios imunoenzimáticos (ELISA e Dot-Blot) e estudo epidemiológico no Estado do Ceará. Tese de Doutorado, Universidade Federal de Minas Gerais, Belo Horizonte, MG. 115p.

Preziuso S., Taccini E., Rossi G., Renzoni G. \& Braca G. 2003. Experimental maedi visna virus infection in sheep: a morphological, immuno-histochemical and PCR study after three years of infection. Eur. J. Histochem. 47:373-378.

Reilly L.K., Baird A.N. \& Pugh D.G. 2002. Diseases of the musculoskeletal system, p.238-240. In: Pugh D.G. (Ed.), Sheep and Goat Medicine. W.B. Saunders, Philadelphia.

Reina R., Berriatua E., Luján L., Juste R., Sánchez A., Andrés D. \& Amorena B. 2009. Prevention strategies against small ruminant lentiviruses: an update. Vet. J. 182:31-37.

Ricarte A.R.F., Andrioli A.A., Pinheiro R.R., Báo S.N., Silva J.S., Braz S.V., Name K.P.O., Lima-Verde I.B., Brito I.F., Dias R.P., Freitas Aguiar T.D., Dantas T.V.M., Araújo S.A.C., Cavalcante D.M.L.P., Paula N.R.O. \& Teixeira M.F.S. 2010. Avaliação imunohistoquímica e ultraestrutural de gametas e embriões caprinos infectados com o Caev. Arqs Inst. Biológico, São Paulo, 77(2):217-223.

Rimstad E., East N.E., Torten M., Higgins J., Derock E. \& Pedersen N.C. 1993. Delayed seroconversion following naturally acquired caprine arthritis-encephalitis virus infection in goats. Am. J. Vet. Res. 54:1858-1862.

Rimstad E., East N., DeRock E., Higgins J. \& Pedersen N. 1994. Detection of antibodies to caprine arthritis encephalitis virus using recombinant gag proteins. Arch. Virol. 134:345-356.

Rowe J.D. 1999. Epidemiology of the CAEV: horizontal transmission of the virus. In: Proceedings of the 26th World Veterinary Congress, WVA, Lyon, France.

Rowe J.D., East N.E., Franti C.E., Thurmond M.C., Pedersen N.C. \& Theilen G.H. 1992. Risk factors associated with the incidence of seroconversion to caprine arthritis-encephalitis virus in goats on California dairies. Am. J. Vet. Res. 53:2396-2403.

Rutkoski J.K., Werenicz R., Reischak D., Wendelstein A.C., Moojen V. \& Ravazzolo A.P. 2001. Detecção da infecção pelo vírus da artrite-encefalite caprina: imunodifusão em ágar e reação em cadeia da polimerase com "primers" degenerados. Arq. Bras. Med. Vet. Zootec. 53(6):635-640.

Silva M.L.C.R., Castro R.S., Maia R.C., Nascimento S.A., Gomes A.L.V. \& Azevedo S.S. 2013. Lentivírus em caprinos leiteiros do semiárido paraibano: prevalência de anticorpos, fatores de risco e detecção molecular. Pesq. Vet. Bras. 33:1-6.

Sims L.D., Hale C.J. \& McCormick B.M. 1983. Progressive interstitial pneumonia in goats. Aust. Vet. J. 60(12):368-371.

Smith M.C. \& Sherman D.M. 1994. Caprine arthritis encephalitis, p.73-79. IN: Ibid. (Eds), Goat Medicine. Lea and Febiger, Philadelphia.

Souza K.C. 2010. Artrite-encefalite caprina: infecção experimental via inseminação artificial e acompanhamento clínico e sorológico. Dissertação de Mestrado, Centro de Ciências Agrárias e Biológicas, Universidade Estadual Vale do Acaraú, Sobral, CE. 99p.

Souza K.C., Pinheiro R.R., Santos D.O., Brito R.L.L., Rodrigues A.S., Sider L.H., Paula N.R.O., Avila A.A., Cardoso J.F.S. \& Andrioli A. 2013. Transmission of the caprine arthritis-encephalitis virus through artificial insemination. Small Rumin. Res. 109:193-198.

Tigre D.M., Campos G.S. \& Sardi S.I. 2006. Isolamento e identificação do vírus da Artrite Encefalite Caprina, a partir do co-cultivo de células mononucleares do sangue com células de membrana sinovial de cabra. Revta. Cient. Méd. Biol. 5(2):124-131.

Traldi A.S., Loureiro M.F.P., Capezzuto A. \& Mazorra A.L. 2007. Métodos de controle da atividade reprodutiva em caprinos. Revta Bras. Reprod. Anim. 31(2):254-260.

Von Mockenhaupt C. \& Bauer K. 1967. Untersuchungen zur Caprinen Arthritis-Enzephalitis in Bayern und des Einflusses seuchen-hygienischer Massnahmen auf den Verlauf dieser Krankheit. Tierärztl. Umschau 42(12):966-970.

Zanoni R.G., Vogt H.R., Pohl B., Bottcher J., Bommeli W. \& Peterhans E. 1994. An ELISA based on whole virus for the detection of antibodies to small-ruminant lentiviruses. Zentbl. Veterinärmed. B 41:662-669. 